\title{
¿CÓMO DIAGNOSTICAR LA OBSTRUCCIÓN INTESTINAL?
}

Roy Riascos C, M.D. Santiago Martínez J, M.D. Rene González M, M.D.

El íleo intestinal es una manifestación frecuente que se presenta asociada con la mayor parte de las afecciones abdominales y, en algunas ocasiones, torácicas y pélvicas. Como tal, no es una entidad nosológica sino más bien un signo dentro del espectro particular presente. Es imprescindible, por tanto, tener un conocimiento amplio acerca de esta entidad y su reconocimiento. La radiología simple de abdomen es una de las principales armas en la confirmación de los diferentes tipos de 1́leo intestinal; de hecho, como estudio inicial, constituye el procedimiento de primera elección y es mandatorio.

Etimológicamente, íleo significa «cólico intestinal», pero en la práctica quirúrgica define la oclusión intestinal, con diferentes grados de intensidad y debido a múltiples causas. Se clasifica en dos grandes grupos: adinámico o paralítico y obstructivo o mecánico. El primero consiste en la parálisis de la musculatura lisa, sin que exista una causa estructural que impida el paso del contenido intestinal. Por su parte, el íleo mecánico es originado por la obstrucción parcial o total de la luz intestinal, bien sea por causa endoluminal o extrínseca. Las causas de uno y otro tipo de íleo son múltiples; sin embargo, el íleo paralítico se presenta con mayor frecuencia después de una cirugía (íleo postoperatorio) o a consecuencia de condiciones tales como desequilibrio hidroelectrolítico, inflamación localizada (por ejemplo, apendicitis) o generalizada (peritonitis), dolor y trauma. Con respecto a la obstrucción intestinal, sus causas más comunes son bridas (70\%), hernias encarceladas $(10 \%)$ y neoplasias $(5 \%)$.

Postgrado de Radiología e Imágenes Diagnosticas Fundación Universitaria de Ciencias de la Salud.

Servicio de Radiología e Imágenes Diagnosticas Hospital de San José.
En la radiografía de abdomen simple se obtienen tres proyecciones básicas: AP en decúbito supino, AP en bipedestación y PA de tórax en bipedestación. La primera tiene por objeto documentar la dilatación de asas intestinales y la distribución del gas; en algunos casos, como en la peritonitis se pueden observar signos de líquido libre en la cavidad o edema de las asas. La segunda proyección busca determinar si existen niveles hidroaéreos (signo de Kloiber) y en qué forma se distribuyen. La última, es indispensable para identificar neumoperitoneo y para descartar afecciones torácicas que tengan repercusión abdominal (por ejemplo neumonías basales, pleuritis, infarto agudo del miocardio). Después de analizar el estudio radiológico el interpretador debe estar en capa-

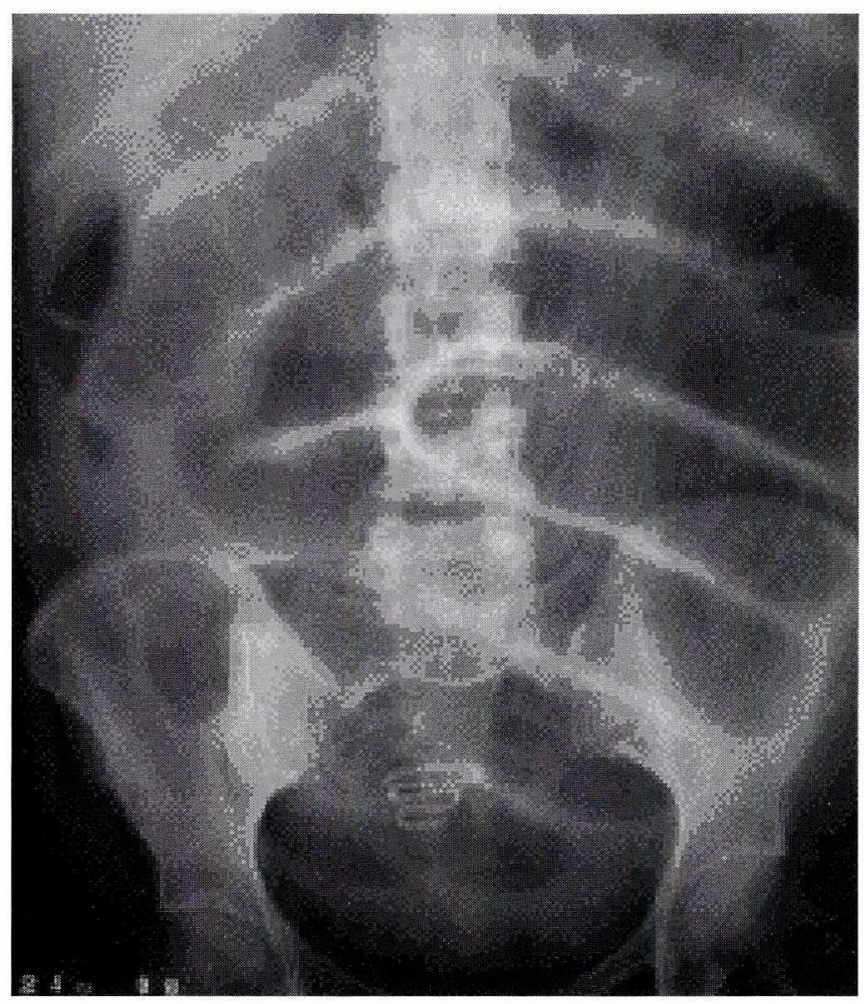

Figura 1. Proyección AP en decúbito supino en donde se evidencia gran dilatación de asas delgadas (mayor a $3 \mathrm{~cm}$ ) con ausencia de gas distal en caso de íleo obstructivo. 


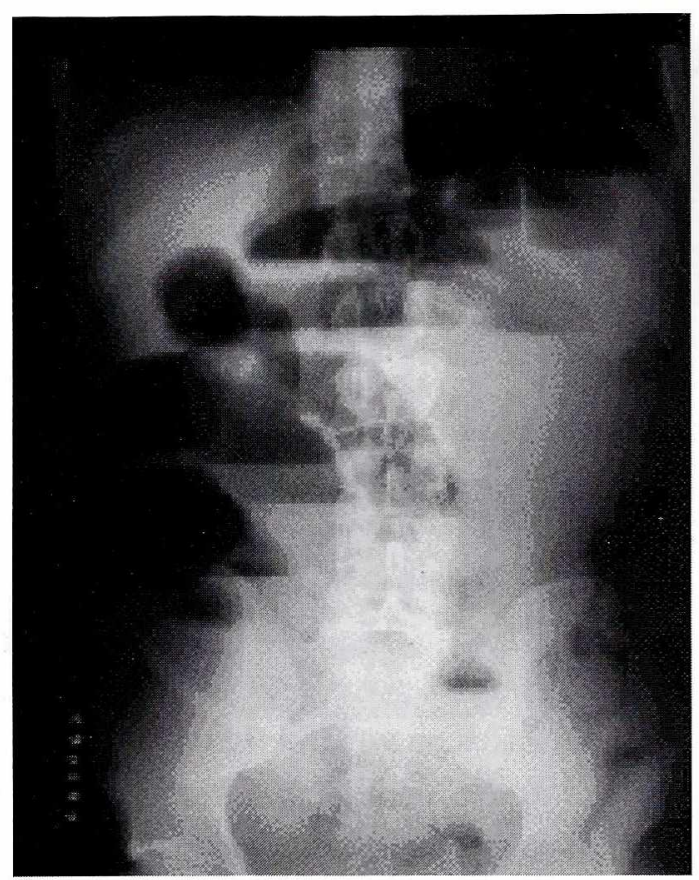

Figura 2. Proyección AP en bipedestación, donde se observa niveles hidroaéreos escalonados en un paciente con íleo obstructivo

cidad de determinar si existe o no un íleo y si es de tipo adinámico u obstructivo.

Para referirse al patrón radiológico del intestino delgado normal, se ha popularizado la regla de los 3 (tres), es decir, que el espesor de la pared intestinal debe ser menor de $3 \mathrm{~mm}$, el grosor de las válvulas conniventes menor de 3 $\mathrm{mm}$, el diámetro de las asas delgadas menor de $3 \mathrm{~cm}$ y menos de tres niveles hidroaéreos por radiografía.

\section{Signos radiológicos}

Los signos distintivos del 1́leo adinámico en los estudios radiológicos son: distensión global de asas intestinales, formación de niveles hidroaéreos no escalonados, presencia de gas en el colon y el recto y, edema de la pared de las asas intestinales (mayor de $3 \mathrm{~mm}$ ), cuando hay peritonitis.

En cuanto al íleo obstructivo, los hallazgos más relevantes incluyen dilatación de asas intestinales (diámetro mayor de $3 \mathrm{~cm}$ ), formación de niveles hidroaéreos escalonados y ausencia de gas distal al sitio de la obstrucción.

Estos datos, aunque típicos, no son específicos. Existen muchos otros signos visibles en la radiografía simple de abdomen que están asociados con una u otra patología y ayudan al diagnóstico, pero no serán mencionados porque se alejan del objetivo de este artículo.

\section{Consideraciones adicionales}

El término íleo biliar se refiere específicamente a la condición en la que tiene lugar el paso de un cálculo biliar de gran tamaño, a través de una fístula bilioentérica, y su posterior alojamiento en la válvula ileocecal, lo que produce una obstrucción.

Por último, algunas condiciones pueden inducir errores diagnósticos, como son la aerofagia, el uso de sonda nasogástrica, la realización de un tacto rectal, la presencia de asas centinelas y ciertas condiciones postquirúrgicas.

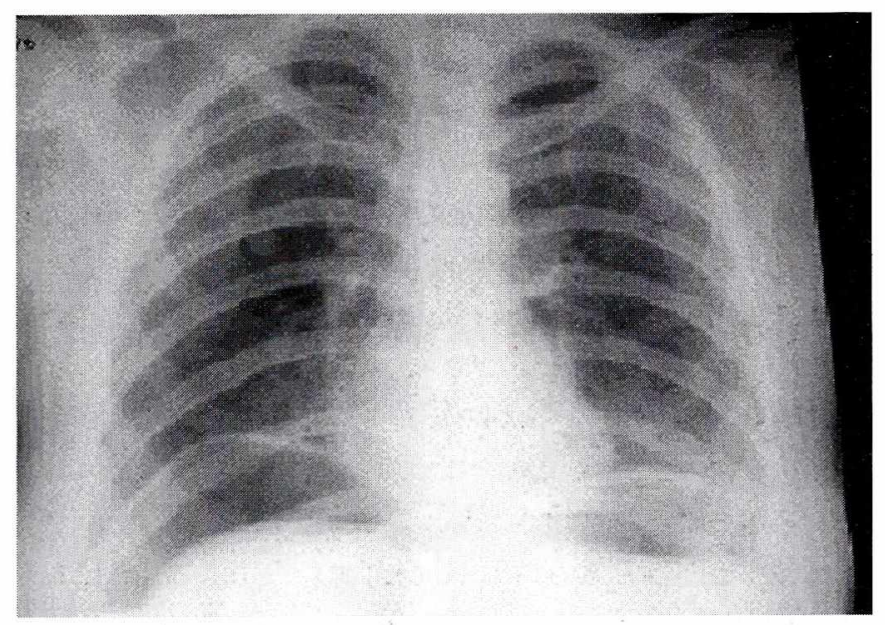

Figura 3. Proyección PA de tórax en bipedestación, donde es evidente la presencia de cámaras de gas subfrénicas, compatibles con neumoperitoneo.

\section{Bibliografía}

Weissleder R, Rieumont M, Wittemberg J. Primer of Dianostic Imaging. 2nd ed. Saint Louis, USA: Mosby; 1997.

Katz D, Math K, Groskin S. Radiology Secrets. Filadelfia, USA: Hanley \& Belfus; 1999.

Teschendorf W. Tratado de Diagnóstico Diferencial

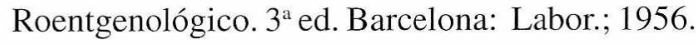

Teplic J, Haskin M. Roentgenlogic Diagnosis. 2a ed. London:WB Saunders; 1971.

González R. Manual de Imagenología, Ediciones Rosaristas.1987. 